\title{
RELIABILITY OF DTMS OBTAINED WITH MOBILE FAST SURVEYS TECHNIQUES
}

\author{
Silvia La Placa, Elisabetta Doria
}

DICAr - University of Pavia, Via Ferrata 3, 27100 Pavia, Italy

\author{
Commission II
}

KEY WORDS: fast survey, ground modelling, landslide, water canalizations, DTM.

\begin{abstract}
:
The contribution addresses the issue of the integrated survey aimed at three-dimensional modeling for the documentation of different types of terrain through the analysis of two case studies located in the province of Pavia - Italy. The techniques of aerial photogrammetric acquisition SfM (UAVs), Terrestrial Laser Scanner (TLS) and Mobile (MLS) are now consolidated and widely used, managing to meet the needs of documentation of land levelling, monitoring, and analysis of landslide volumes. The two case studies present difficulties due to a strong inclination of the land and extensive presence of vegetation in the first case and to a strong presence of agricultural canalizations in the second case. The data processing phase focused on the comparison between MLS and close-range photogrammetry, while the acquisitions from TLS were used as control data. This acquisition method allows avoiding the process of approximation and reconstruction of the DTM under the vegetation, ensuring the correctness of the data relating to the ground course. The database allows the generation of highly reliable DTMs using specific point cloud modeling and processing software. Fast survey instruments are ideal in large areas or in hilly areas where sub-vertical sections and covered by vegetation are often present, difficult to detect only with close-range photogrammetry.
\end{abstract}

\section{INTRODUCTION}

The proposed contribution aims to clarify some aspects of broader research whose ambition is to define digital representation strategies that can be used to analyse, monitor, and enhance the landscape. In particular, the text addresses the issue of the integrated survey aimed at three-dimensional modeling for the documentation of different types of terrain through the analysis of two case studies located in Pavia, Italy (see Figure 1) (Parrinello, 2003; Parrinello, Picchio, 2018).

The Province of Pavia includes geographically different natural landscapes offering emblematic case studies to develop research activities in the research field of documentation.
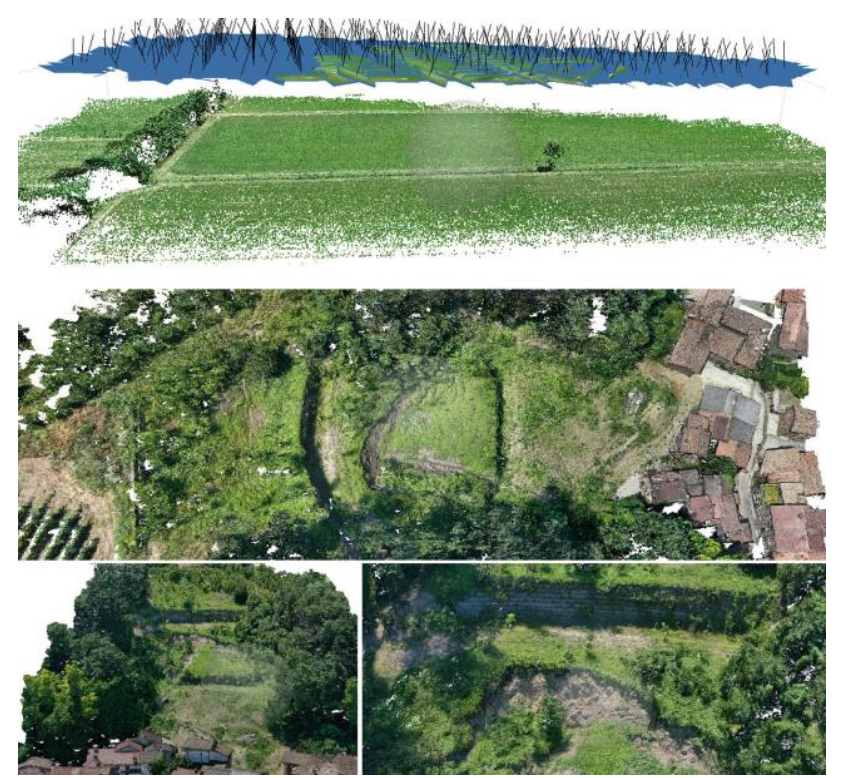

Figure 1. Images of the two case studies analysed in this phase of the ongoing research: above, plain of Pavia in Po valley; below, Oltrepo' Pavese landslide.
An extensive flat land characterizes the agricultural landscape north of the city of Pavia. A continuous expanse of fields, alternating with waterways, defines a complex landscape system, which the gaze hardly focuses on due to the lack of vertical references (Cavallo, 2011). The historic water canalization, since Roman times (Trotta, 2017; Briaschi 2021) has allowed the economic and productive development of the area and today represents its identity (Oldani, 2020). South of the Po River the territory loses its horizontal propensity in favour of a hilly landscape. The geologically recent evolution of these hills and their litho-structural properties facilitate the onset of landslides. (Cagnoni, Cazzaniga, Fossati, 2004). The agricultural vocation of the flat land and its extension invites us to define long-term control and management systems for canals and waterways. The predisposition to landslides in the hilly area stimulates the design of effective and rapid documentation and quantification of subsidence methods. The digital survey tools (TLS, MLS, UAV, as visible in Figure 2), suitably integrated, offer a fundamental knowledge base from which to develop experiments for the construction of three-dimensional models of analysis and management of open spaces.

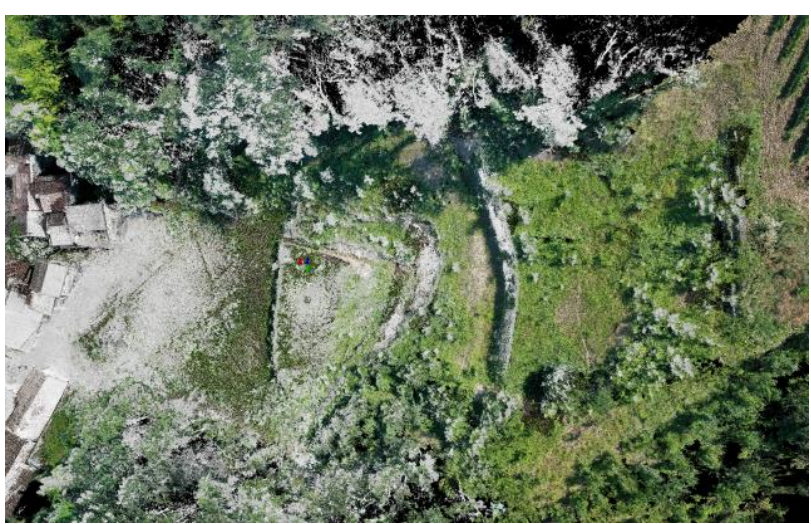

Figure 2. Top view of the point cloud of the first case study, the landslide slop. This point clouds has been created by the different survey instruments. 


\section{RELATED WORKS}

The techniques of $\mathrm{SfM}$ aerial photogrammetric acquisition (UAVs), Terrestrial Laser Scanning (TLS) or Mobile Laser Scanning (MLS) are nowadays consolidated and widely used; these techniques are used for the documentation of land levelling, monitoring and analysis of landslide volumes (Conforti Andreoni, Massari, Polteca, 2003; Babić, Pribičević, Đapo, 2012). The growing technological development in the field of digital fast survey documentation leads to the introduction on the market of increasingly performing tools and instruments. Lidar mobile mapping system (MLS) creates a threedimensional point cloud from the surrounding area thanks to the movement of the technical operator who uses the instrument and motion-tracking navigation devices. The MLS navigation system is typically based on the global navigation satellite system (GNSS) and tracks the trajectory producing 3D point clouds (Kukko, Kaartinen, Hyyppä, Chen, 2012). The latest generations of MLS allow to obtain a point cloud of medium density and compared to the clouds of traditional TLS, metric reliability with the advantage of operating in a very short time. Surveying in motion is what makes MLS suitable for surveying and modelling large areas. Using manual MLS, physically carried by the operator, it is also possible to reduce the problem of the ground covered by vegetation by moving the instrument at ground level. This is especially useful when land is the object of study. In these cases, using a drone would not be possible to understand the land level differences. Nowadays mobile laser scanners could represent the survey instruments for high metric precision DTMs production in a short time (Toschi, Remondino, Orlandini, 2015). The aim of the research is to evaluate the potential of fast laser scanning survey techniques for monitoring landslides and open extended areas. MLS provides fast, accurate, and very efficient in collecting this kind of data and they represent nowadays the "extension between the gap of aerial and terrestrial laser scanning" in terms of the level details, time of acquisition, and quality of data captured (Fuad, Yusoff, Zam, Aspuri, Salleh, Ismail, Abbas, Ariff, Idris, Majid, 2018). This temporal advantage makes it possible to operate on large areas, as in the case of detailed documentation of the hydrographic network, or as in the case of having to promptly acquire data relating to a landslide. These two case studies are different from each other in terms of ground characteristics and possible critical scenarios, but both require extensive survey techniques with a favourable data quality ratio and acquisition time. In the field of technological optimization, there are still open problems regarding the acquisition, the data processing, and the procedures for generating DTMs starting from Digital Surface Models (DSM). The problem of extracting a DTM from laser scanner point cloud is widely studied (Vallet, Papelard, 2015), and the main challenges highlighted related to the proposed research are:

1. Post-production registration of overlapping acquisitions;

2. The filtering of ground and the removal of the offground points.

In the case studies presented, these difficulties are due to the environment itself: the massive presence of vegetation and the water in natural landscapes, visible in Figure 3, do not allow the correct view of the land from instruments at close range. To optimise the recognition of the terrain, filtering techniques of the point cloud are used which can be carried out through specific algorithms (Vallet, Papelard, 2015) or manually (Fuad, Yusoff, Zam, Aspuri, Salleh, Ismail, Abbas, Ariff, Idris, Majid, 2018). In the proposed research, both methods were tested to make a comparison of the results obtained.

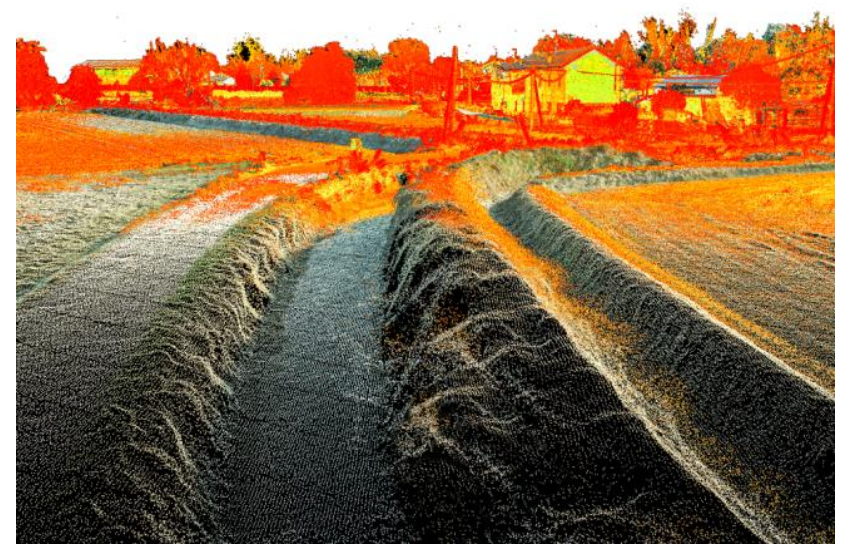

Figure 3. Point cloud integrated between MLS and drone photogrammetry. Second case study: irrigation systems of the agricultural system of the Pavia plain.

\section{METHODOLOGY}

This section describes land survey and digital modelling starting from data obtained with terrestrial laser scanning instrumentation (FARO CAM2 S150), mobile laser scanner (Stencil 2-16 KAARTA), and using close range UAV photogrammetry techniques (DJI Mavic) (Bitelli, Dubbini, Zanutta, 2004; Parrinello, Picchio, 2019). The two case studies present difficulties due to a strong inclination of the land and extensive presence of vegetation in the first case, and to a significant presence of agricultural canalizations in the second case.
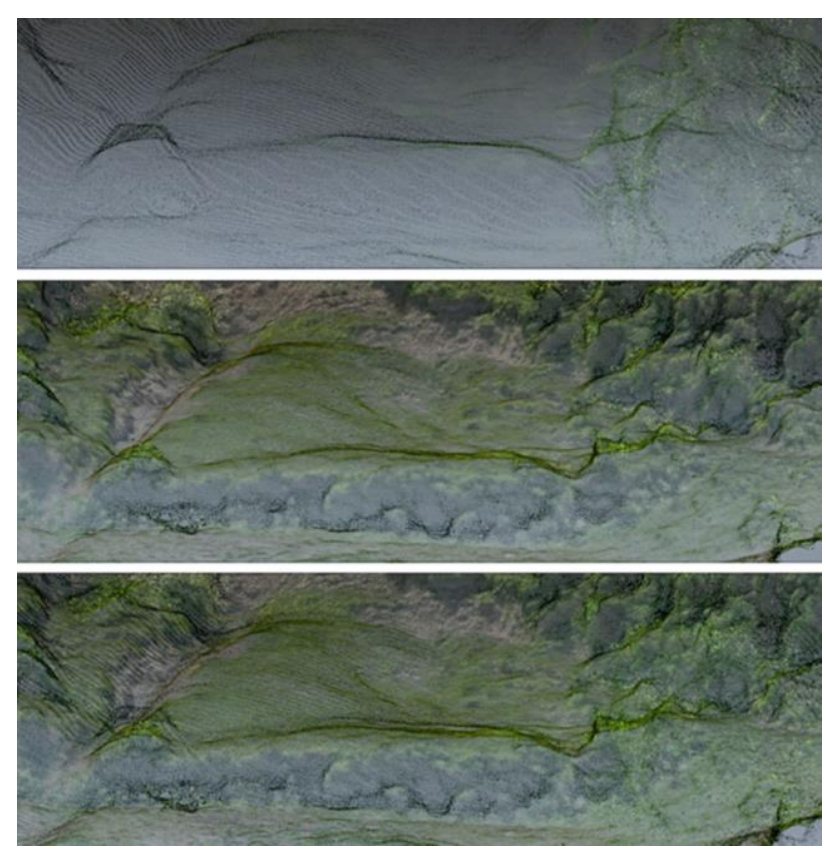

Figure 4 . The tools to create a digital survey must be carefully compared to them in order to obtain the correct level of detail necessary for the various research and environmental management activities.

The data processing phase focused on the comparison between MLS and close-range photogrammetry (see Figure 4), while the acquisitions from TLS were used as control data. The point clouds have been integrated based on targets strategically positioned and visible by all the tools used. Using the MLS, it was possible to conduct the survey by moving under the trees' crowns and overcome the problem of the lack of data, which 
would be generated by the acquisition from the drone. The aerial camera would see the trees' crowns, failing to see the actual land course. This acquisition method allows avoiding the process of approximation and reconstruction of the ground under the vegetation, ensuring the correctness of the data relating to the ground course. The database allows the generation of highly reliable DTMs using specific point cloud modelling and processing software.

\subsection{First case study: hilly landslide covered by vegetation}

The first case study analysed concerns a landslide in the hilly area of Pavia and close to numerous houses, which were evacuated and only subsequently collapsed due to landslides. There are two types of vegetation: on the landslide sides, there is a dense forest with tall trees, while above the landslide, there are low seasonal shrubs, which do not prevent the soil analysis even with instrumentation UAV.

3.1.1 Acquisition method: The vegetations presence makes the UAV instrumentation unsuitable for generating a reliable DTM to monitor the progress of the landslide and its perimeter. The detection method followed a process divided into four different phases:

1. Acquisition of GNSS points with GPS receiver also detectable by other instruments;

2. TLS survey with FARO CAM2 S150 instrument of the landslide portion close to the houses and roads not affected by the subsidence to have a highly reliable point cloud as an alignment base. This survey managed to acquire main and secondary embankment, already the subject of consolidation interventions in the past;

3. Close range SfM photogrammetric survey with DJI Mavic drone, for the analysis of the landslide, clearly visible in winter without seasonal vegetation;

4. MLS survey with STENCIL KAARTA 2-16 instrument, including both the portion of landslide and the landslide in the woods, in which landslide ridges are contained and historicized.

Before proceeding with the survey, the operators prepared the positioning, number, and types of targets. In the open spaces and on the landslide area, where possible, recognizable at a great distance target were positioned to perform aerial photogrammetry. The operators placed three-dimensional spherical targets on vertical support. These targets are visible from ground instruments, even if the ground has hollows and low vegetation. Lastly, other targets have been placed for the ground-based MLS survey.

Targets are black and white numbered progressively and attached to the trees and special supports. Targets, thus numbered, facilitated orientation in the woods and the registration process of scans performed with the KAARTA MLS Stencil tool.

The MLS survey with KAARTA Stencil, the use of which in open areas had already been proven both on urban and rural portions (Dell'Amico, La Placa, 2019), required a careful study of the paths. The operator had to move inside the woods and on the landslide, in uneven terrain with numerous fallen trees blocking the marked paths. The operator walked by defining circular rings to reduce the drift error of the instrument. The paths made it possible to acquire all the landslide crests in the woods and, where possible, the landslide body itself.

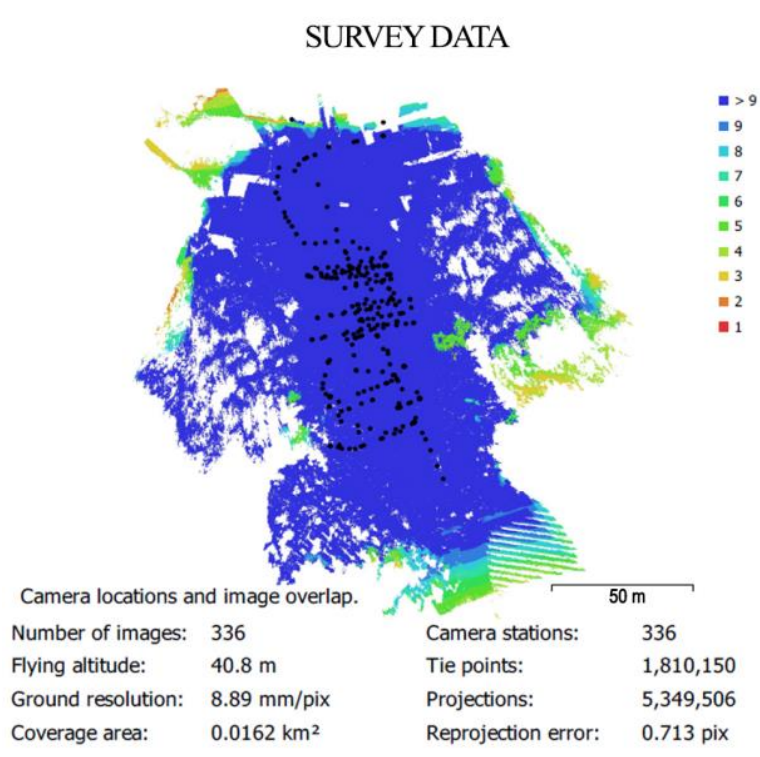

\section{GROUND CONTROL POINTS}

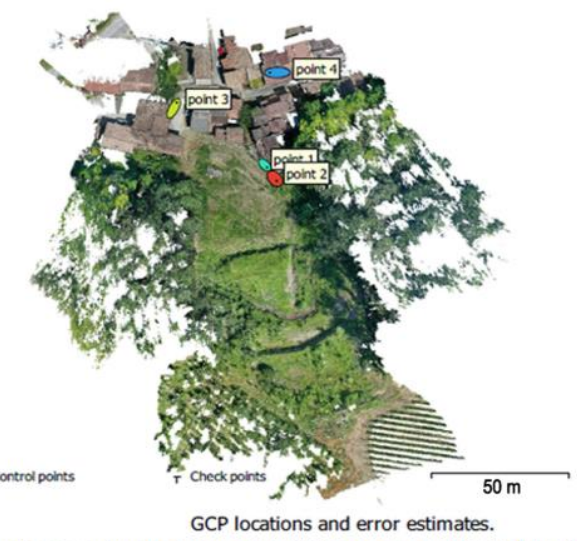

$Z$ error is represented by ellipse color. X,Y errors are represented by ellipse shape. Estimated GCP locations are marked with a dot or crossing.

\begin{tabular}{|l|l|l|l|l|l|}
\hline Count & X error $\mathbf{( c m )}$ & Y error $(\mathbf{c m})$ & Z error $(\mathbf{c m})$ & XY error $(\mathbf{c m})$ & Total $(\mathbf{c m})$ \\
\hline 4 & 3.10546 & 2.56317 & 2.64019 & 4.02663 & 4.81501 \\
\hline
\end{tabular}

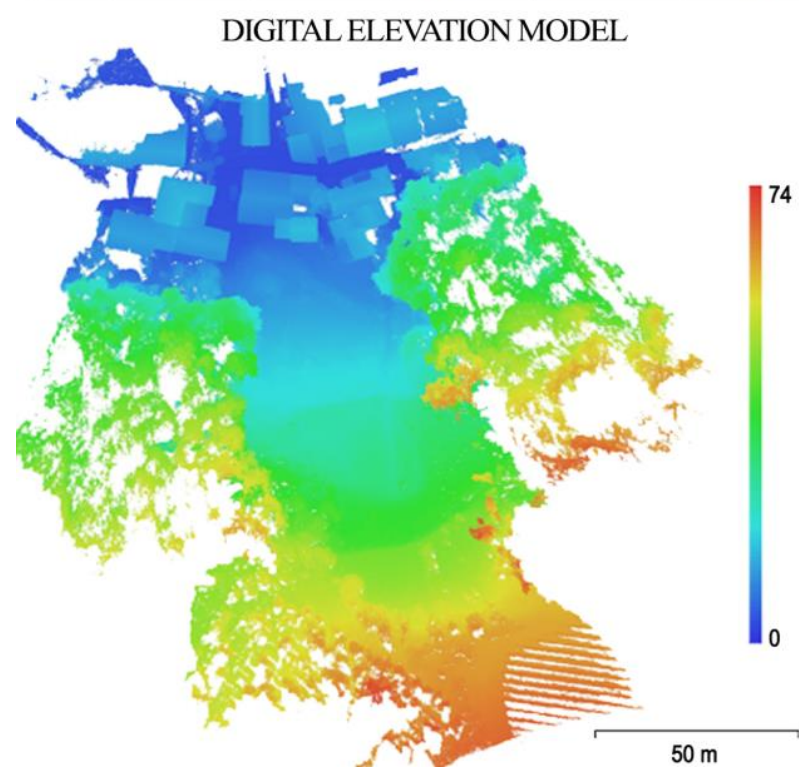

Figure 5. Drone photogrammetry processes and analysis concerning the first case study. 
3.1.2 Data Registration: In the registration phase the data obtained from the different instruments were merged, based on the TLS data, and registering one database at a time. The drone photographs, processed using the SfM technique with Agisoft Metashape software, generated a points cloud. This one was oriented according to the GPS points taken during the survey phase and exported to be opened with the Leica Cyclone software. The photogrammetric model is made up of 366 aligned photographs and covers an area of 0.0162 square $\mathrm{km}$. The drone flew at an average distance from the ground of $40.8 \mathrm{~m}$, and the result is a point cloud Tie Points: $1,810,150$ points and Dense Cloud: 465,939,076 points. The CAM2 SCENE FARO software made it possible to record the TLS point cloud, which then was imported into the Leica Cyclone. Using Cyclone, the operator performed the registration between the TLS point cloud, homescan, and the photogrammetric point cloud, using targets and notable points distributed with a minimum error of $0.014 \mathrm{~m}$ and a maximum error of $0.092 \mathrm{~m}$. The four-point clouds, obtained from MLS Stencil KAARTA, were first registered together, and verified, and subsequently joined to the previously created database. In this way, the global point cloud includes both the terrain relief (TLS, MLS) and the tree frond relief (UAV). The union of the final pair of the MLS scans from the ground gave $0.027 \mathrm{~m}$ as a minimum error on points and $0.065 \mathrm{~m}$ as a maximum error. The final point cloud contains information on the ground and the trees, including the trunk's inclination, thanks to the TLS and MLS data.

\subsection{Second case study: flat land without vertical references and with water reflections}

Hydraulic works insist on this landscape spread along the canals and hidden by the horizontal inclination of the whole. The complex system represents an identity heritage, which requires the definition of appropriate documentation, organization, and management strategies. The issue of documentation reliability is of particular importance: on the one hand, the object of study includes different scales of representation from large extensions to the details of minor hydraulic works; on the other, the natural elements that make up the landscape undergo continuous transformations. The operator risks acquiring contiguous portions at different times of the year. Seasonal conditions or possible sudden and traumatic events transform the landscape. The overall digital duplicate, therefore, tells heterogeneous situations, without specifying that they correspond to different year moments. Most of the waterways that run through the fields have a small width (about $1 \mathrm{~m}, 1.5 \mathrm{~m}$ ) and seasonal operation. The sparse rows of trees of the flat land insist on the banks of the largest reservoir canals, offering few visual horizons. These characteristics, combined with the reflection problems that water generates in the acquisition tools, make the landscape of the Pavia flat land an opportunity to develop a new integrated acquisition approach.

3.2.1 Acquisition method: The acquisition campaign concerned a rural settlement in the north of Pavia located along the Naviglio Pavese water system.

In this area is evident the symbiotic relationship between the development of the buildings and the continuity of the irrigation canals. The urban area, the agricultural plots, and the water jump on the Naviglio basin have been documented by operating with different tools as visible in Figure 6 (TLS, MLS, UAVs, GPS rod). The large targets made it possible to integrate the various data obtained to generate an overall and metrically reliable point cloud. The experimentation area is a rectangular plot of 3.5 hectares, crossed by two water canals of different depths, orthogonal to each other.
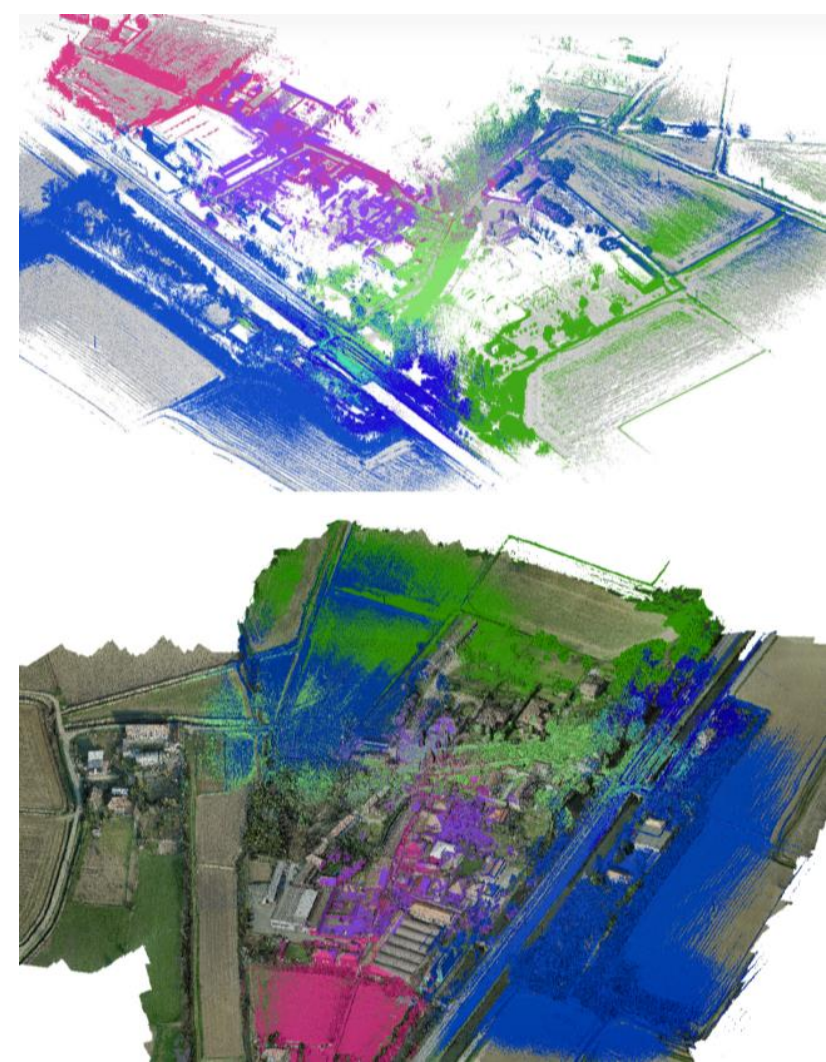

Figure 6. Above: five different and merged MLS point clouds without RGB data. Below: the final point cloud made from the integration between MLS and UAV data.

Inside the area, a row of trees is visible, typically located on the embankment of the major canal, and a single tree, next to which there is an iron lock and a stone level crossing. The area has few significant points, and so the choice of the number and type of target, $50 \times 50 \mathrm{~cm}$, to be placed has assumed great importance. Once the targets on the ground were arranged, the acquisition methodology involved an MLS and a drone. The first instrument tested was the Stencil KAARTA mobile laser with LIDAR technology.

The lack of vertical reference points created difficulties in the acquisition phase, solved by following closed paths. Presence of water did not generate problems in the instrument: the acquired data does not have mirrored portions, a situation that typically occurs using fixed station lasers.

Documentation operations lasted less than an hour, the time needed to walk the banks of the canals under investigation. The morphometric survey was then carried out with the DJI Phantom 4 RTK (Real-time kinematic positioning) drone. RTK technology guarantees a high level of reliability of the drone position concerning the area subject to documentation: it acquires the signals coming from the satellites and replicates them on the receivers of its network, minimizing the measurement error up to an accuracy of approximately $1 \mathrm{~cm}$.

The documentation took place in flight plan mode set for 3D photogrammetry. The drone reached a height of 35 meters to overcome the few obstacles of the lateral trees and obtain a photographic quality capable of describing in detail the mentioned unevenness of the ground. One battery was sufficient to cover the experimentation area, thanks to this, it was possible to avoid any errors due to the landing and repositioning of the aircraft for the new departure. The flight plan produced 358 photos, taken with an overlap of $70 \%$ to optimize the postproduction work despite the significant points lacking. 
3.2.2 Data Registration: The acquisition campaign made it possible to obtain two three-dimensional databases, which can be integrated through common points (targets). Taking advantage of the precision guaranteed by the DJI Phantom 4 RTK, the point cloud obtained with MLS was oriented on that of the UAV, to create an overall digital space from which to develop analyses and considerations on the flat terrain. The clouds were recorded with different programs and then integrated on Leica Cyclone software. The data obtained from the MLS were first converted and analysed on Cloud Compare software and then recorded on Leica Cyclone software (Table 1). The photogrammetric aerial data were processed on Agisoft Metashape software. Other software made it possible to view the integrated databases and proceed with multiple experiments. A first test was conducted on the Agisoft Metashape software, which allows you to work, keeping the databases separated in chunks. The two chunks, one is the point cloud from MLS and the other is the point cloud from UAV, have been aligned and registered, keeping the option of managing them separately.

The KAARTA Stencil cloud returns the embankments profile with greater detail than the close-range photogrammetric point cloud, while the crowns of the trees, also visible from MLS, acquire definition thanks to the aerial acquisition.

Contiguous sections (created every $2 \mathrm{~m}$ ) have articulated the database, first cutting the overall model orthogonally and transversely to the major canals. The sections highlight the high adherence of the two databases around the control points (targets common to the individual databases) and decrease as you proceed towards the ends of the cloud. The correspondence of the two databases occurred with the distance computation process: in the portions that describe the embankment's immediate surroundings, the clouds have total adherence; a difference, less than $4 \mathrm{~cm}$, is recorded in the internal and upper portions of the embankments.

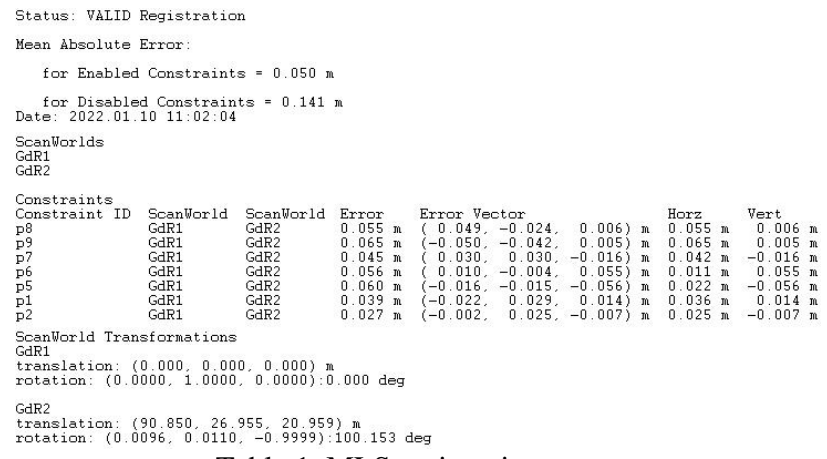

Table 1. MLS registration report

\subsection{Modeling of the DTM}

The point clouds (verified for the two case studies dealt with) become reliable three-dimensional models of reality. These models, which can be orbited and interrogated, make it possible to know the unevenness and slopes of the terrain, extrapolating mean information for the construction of a land management DTM in different areas. The databases obtained from the MLS tools allow to reach a high level of detail of the measurement and return more information than is necessary for the management of the land. Therefore, some elaborations are necessary to optimize the visualization, read the data relating just to the soil, and build highly reliable DTMs. These can be used by technicians with different skills, belonging to bodies, consortia, and administrations. Cleaning the model of all excess acquired data is the first phase of the digital terrain restitution process. Trees and buildings compromise the reading of the terrain and must therefore be delated.
The research tackled the problem of restorative processes by operating in two ways: the manual extraction method and the semiautomatic modeling method. The results were compared to each other to offer an overview, limited to the case studies under investigation, on the advantages and disadvantages of both techniques used for certain types of land.

3.3.1 Manual modeling: The DTM's modeling with manual extraction involves the point cloud cleaning and a modeling process, starting from sections at a constant pitch, exported directly from the point cloud. The process took place with the following methodology:

1. Extraction from the point cloud of regular pitch sections and refinement sections, in points of particular complexity (sections every $50 \mathrm{~cm}$ and refinements at $25 \mathrm{~cm}$ ) - Figure 8;

2. Import of point cloud slices, referenced in threedimensional modeling software, and manual review of section points. This phase produced a series of broken lines, drawn manually (critical analysis of the context), which represent the ground line of the area of interest - Figure 8;

3. Mesh model generation by connecting points close to each other. The model is a surface passing through the selected profile curves - Figure 9.

Manual mode operating makes it possible to redraw sections and floor plans from the integrated cloud. The operator exports the slices directly from the point cloud and then draws the ground levelling. The section's drawing requires considerable time, in contrast to the main objective (pursued up to now) of defining an expeditious methodology for the acquisition and representation of the landscape.

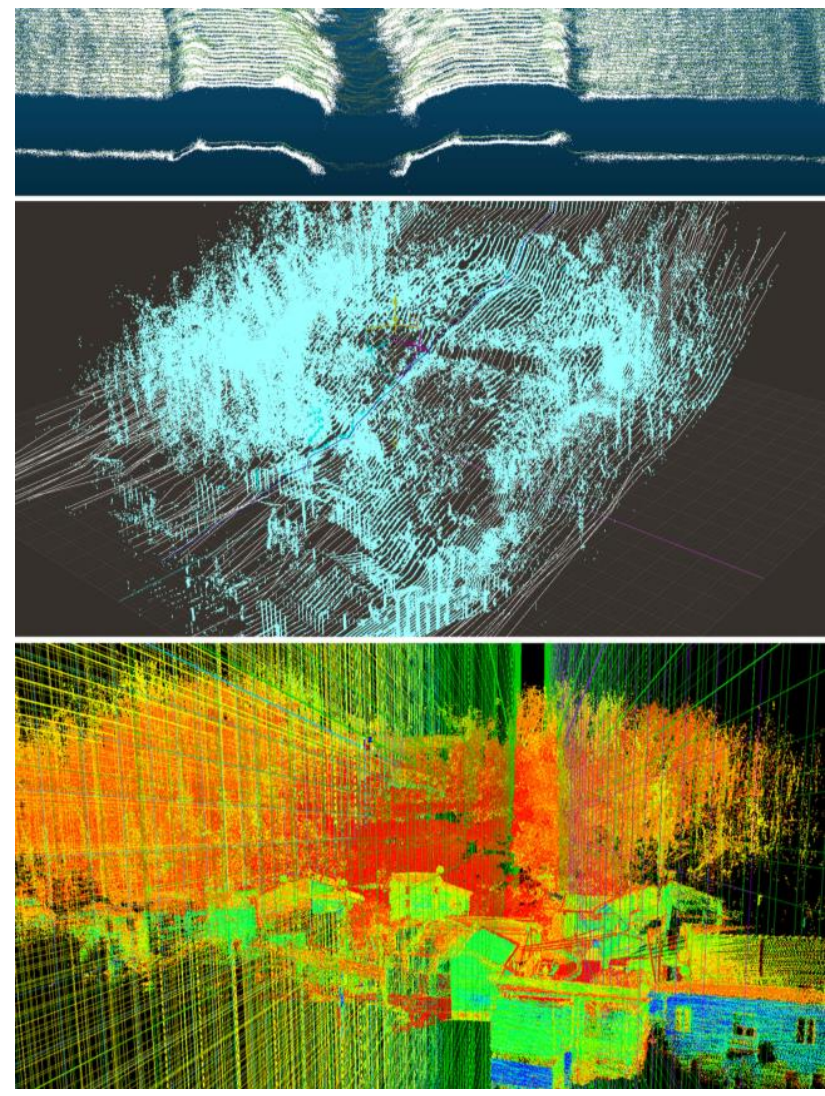

Figure 7. Extraction of sections and manual modeling starting from the points of the point cloud acquired in the field. 
However, this method involves an expert operator, which carries out a critical drawing of the ground, carefully avoiding points belonging to vertical disturbing elements or points incorrectly not eliminated during the noise filtering phase from the database. Although the result was satisfactory, the excessive time required invited us to experiment with an alternative method to speed up the modeling phase of the DTM as well.

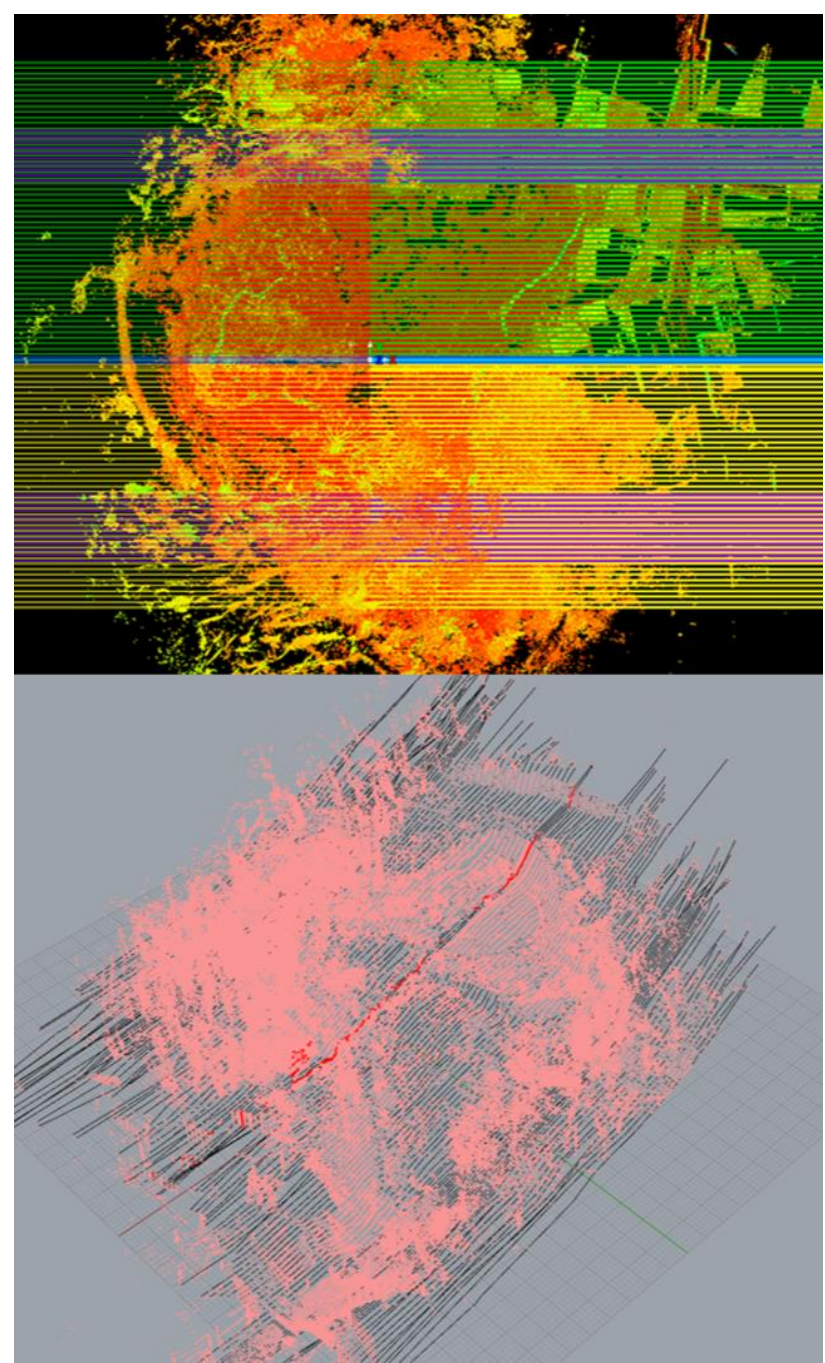

Figure 8. Graphical representation of the process to export point cloud slices.

3.3.2 Semi-automatic modeling: Experiments were carried out to make the processes of information extrapolation from the ground semi-automatic and obtain a DTM generation in a brief amount of time.

The use of automatic/semi-automatic processes must ensure that the final model is legible and reliable metrically, like the model obtained by working manually. The extraction of the soil with special software generally requires an initial phase of disturbing elements eliminations. The operator can clean the point cloud manually or with automatic filtering algorithms (Aschoff 2004) (Wallace 2014) (Zhong, 2017). To speed up the whole process, the operator used "Leica Geosystems' 3DReshaper Point Cloud Processing Software". This software allows you to generate a DTM from the point cloud, without previously removing or filtering the trees and vertical elements. The operator can act just only on some parameters, such as the maximum slopes of the ground, the control on the points, and the stiffness of the patch, to evaluate and define, concerning the research objective, the greater or lesser adherence of the model to the point cloud. The fast times made it possible to carry out nine extraction tests for each case study. In particular, for each survey area irrigation flat land and landslide, the MLS point cloud, the UAV point cloud, and the overall database were imported into the software. For each point cloud, 3 DTMs were created, varying the adhesion parameters of the software.

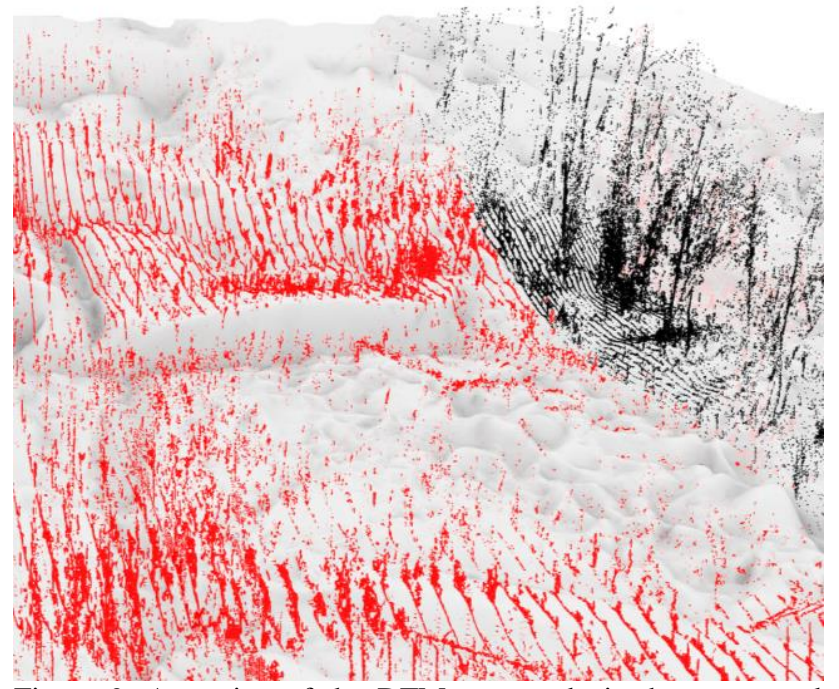

Figure 9. A portion of the DTM extracted via the automated method - software 3D Reshape.

\section{RESULTS}

The use of different point cloud management software (3DReshaper, Cloud Compare, Leica Cyclone, Agisoft Metashape) has allowed us the creation of two-dimensional drawings to interpret the terrain. The high metric reliability of the sections extracted from the point clouds made it possible to:

1. Evaluate in detail even the minimum differences in height present in the case study of the plain, returning valuable information about the direction of the water current;

2. To have a highly reliable metrically based basis on which to develop subsequent analyses and considerations relating to ground instability.

The actions of comparison and validation of the products made it possible to establish, for these case studies, the best database (from MLS, UAV, or integrated) to obtain the most faithful DTM to reality.

Building's elements cannot be modelled automatically with architectural scale detail $(1: 200)$ but must be placed on the ground once they have been modelled manually.

The successful integration of the point clouds from KAARTA and Phantom 4 RTK allows overcoming some specific unsolvable problems in the individual databases. In particular, the woods (landslide area) and light reflections due to water (irrigated flat land area) had generated gaps in the ground.

The 3DR software allows you to reconstruct the missing areas but it produces an approximation, which is to the detriment of the metric reliability of the final model. In addition to this, as seen in the sections of Figure 7, the drone offers a less precise rendering on flat areas, failing to capture the minimum differences in height where there is tall vegetation.

The KAARTA (MLS) data was fundamental to ensure metric accuracy. However, only the MLS instrument could not cover (due to the impossibility of access) all areas of investigation. These not accessible areas were acquired thanks to the drone. 
The data integration, based on the drone cloud (RTK system), has also ensured the metric reliability of the point cloud from which to extract the DTM.
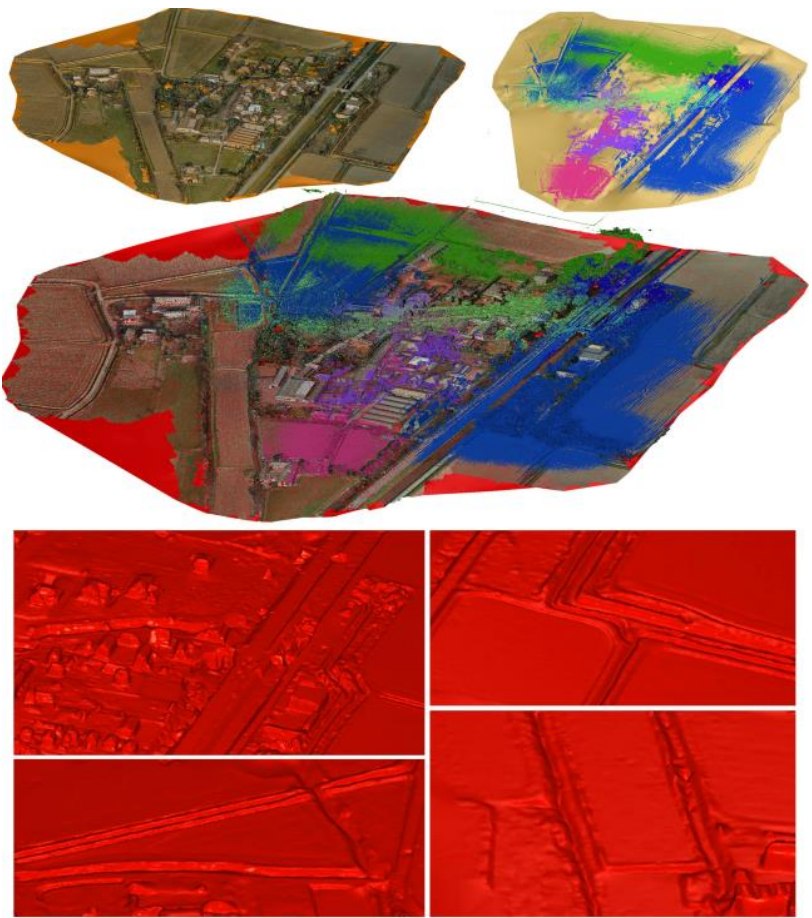

Figure 10. Comparison between DTMs from different point clouds. From above: on the left UAV's DTM, on the right MLS's DTM, at center the integrated database's DTM, below integrated database DTM details.

\section{CONCLUSIONS AND FUTURE WORKS}

The validity of the products - mesh models generated starting from the integration of SfM close range and MLS - underlines the advantages of using fast survey tools, in particular MLS. These instruments are ideal in large areas or in hilly areas where sub-vertical sections and covered by vegetation and they are difficult to detect only with close-range photogrammetry.

The speed of carrying out the experimentation invites us to replicate the research activities on further case studies, evaluating the possibility of applying this methodology to other soil types. The possibility of operating in fast conditions, not only in the acquisition phases but also during all the data processing while maintaining a high level of reliability, represents an undisputed advantage in the approach to large areas or for which it is necessary continuous monitoring. In this sense, the research intends to continue to:

1. Documenting the same portion of the territory in a cadenced manner, to quickly dispose of different digital models, from which to develop maintenance management analyses;

2. Replicating the method by applying it to territorial area that present similar problems in contexts different from those treated in this first experimentation phase.

The continuous technological development, that involves digital instrumentation fields, makes it possible to start activities in critical areas ever with greater ease. The experimentation of integrated methods between the different fast-survey instruments allows obtaining increasingly optimized models, exploiting the potential of the different acquisitions in a single database. The integrated point clouds have a high level of detail, modifiable through filtering, and adaptable to different management needs. The DTMs thus obtained can be used and studied by many professionals and scientific researchers with different goals, allowing them to analyse it at different detail scales.

\section{ACKNOWLEDGEMENTS}

This research was enforced in a collaboration between DJI Enterprise and the University of Pavia for the development of research activities and the promotion of the different ways of using drones for cultural heritage. This collaboration is based on the "Agreement for the development of research activities about the digital documentation of cultural heritage and landscape using drones" between the Department of Civil Engineering and Architecture DICAr of the University of Pavia and iFlight Technology Company Limited, signed in February 2020, lasting three years.

The project is thanks to the collaboration between the Dada-Lab \& PLAY research and teaching laboratories of the University of Pavia - Department DICAr, and the enterprise Leica Geosystems.

We would like to thank Dott. Francesca Picchio for the support during the research activities and for her skills as a certified drone pilot.

\section{REFERENCES}

Aschoff, T., Spiecker H, 2004: Algorithms for the automatic detection of trees in laser scanner data. International Archives of Photogrammetry, Remote Sensing and Spatial Information Sciences, 36(8-W2):71-75.

Babić, L., Pribičević, B., Đapo, A., 2012: Mobile Laser Scanning (MLS) in transport infrastructure documentation and research. Ekscentar (15), 96-99.

Bao, Y., Li, G., Cao, C., Li, X., Zhang, H., He, Q., Bai, L., Chang, C., 2008: Classification of LIDAR Point Cloud and Generation of DTM from LIDAR Height and Intensity Data in Forested Area. ISPRS Archives - Volume XXXVII Part B3b, 2008, XXI ISPRS Congress, July 3-11, 2008, Beijing, China.

Bigatti, G. (eds.), 2020: Paesaggi d'acque in Lombardia. Scritti di Carlo Cattaneo. Milano, IT: Biblion Edizioni.

Bitelli, G., Dubbini, M., \& Zanutta, A., 2004: Terrestrial laser scanning and digital photogrammetry techniques to monitor landslide bodies. International Archives of Photogrammetry, Remote Sensing and Spatial Information Sciences, 35(B5), 246251. ISPRS Archives - Volume XXXV Part B5, 2004.

Briaschi, A., M., 2021: Geografia L'Italia. Vol. V - VI. Milano, IT: BUR Rizzoli.

Cagnoni, A., Cazzaniga, C., Fossati, D., 2004: Conoscenza del dissesto idrogeologico nell'oltrepo' pavese. Congress Oltrepo' Pavese: Suolo, Natura e Acqua, Salice Terme Pavia, 13-14 ottobre 2004

Cavallo, F., L., 2011: Terre, Acque e Macchine. Geografie della Bonifica in Italia tra Ottocento e Novecento. Parma, Diabasis Eds.

Conforti Andreoni, D., Massari, G., Polteca, M., 2003: Generazione di modelli digitali del terreno dalla combinazione di dati lidar da piattaforma aerea e terrestri. National Italian 
Conference ASITA 2003 - "L'Informazione Territoriale e la dimensione tempo". 28-31 ottobre 2003, Verona.

Dell'Amico, A., 2020: The application of fast survey technologies for urban surveying: the documentation of the historic center of Santa Cruz de Mompox. In: Barba S., Parrinello S., Limongiello M., Dell'Amico, A., (eds) D-SITE Drones - Systems of Information on culTural hEritage. For a spatial and social investigation. Pavia University Press, Pavia.

Dell'Amico, A., La Placa, S., 2019: L'applicazione di tecnologie SLAM per il rilevamento di grandi complessi fortificati. In: Parrinello, S., Picchio, F.: Dalmazia $e$ Montenegro. Le fortificazioni Venete nel bacino del Mediterraneo Orientale. Procedure per la conoscenza e la Documentazione Digitale del Patrimonio Storico Fortificato. Pavia: Pavia University Press.

Fuad, N. A., Yusoff, A. R., Zam, M. P. M., Aspuri, A., Salleh, M. F., Ismail, Z., Abbas, M. A., Ariff, M. F. M., Idris, K. M., and Majid, Z., 2018: Evaluating mobile laser scanning for landslide monitoring. Int. Arch. Photogramm. Remote Sens. Spatial Inf. Sci., XLII-3/W4, 211-219, https://doi.org/10.5194/isprs-archives-XLII-3-W4-211-2018.

Kukko, A., Kaartinen, H., Hyyppä, J., and Chen, Y., 2012: Multiplatform approach to mobile laser scanning. Int. Arch. Photogramm. Remote Sens. Spatial Inf. Sci., XXXIX-B5, 483488, https://doi.org/10.5194/isprsarchives-XXXIX-B5-4832012, 2012

Oldani, A., 2020: Acque e paesaggi d'invenzione. Descrizione, meraviglia e nuova interpretazione di infrastrutture $e$ architetture dell'acqua. Melfi (PZ): Libria.

Parrinello, S. 2003: Disegnare il Paesaggio. Esperienze di analisi e letture grafiche dei luoghi. Edifir Edizioni, Firenze.

Parrinello, S., Picchio, F., 2018: Barbianello e Palazzo Nocca. Un progetto di documentazione per lo studio dell'Oltrepò pavese. Edifr Edizioni, Firenze.

Picchio, F., Parrinello, S., 2019: Integration and Comparison of Close Range SfM methodologies for the analysis and the development of the historical city center of Bethlehem. The International Archives of the Photogrammetry, Remote Sensing and Spatial Information Sciences. vol. XLII-2/W9, p. 589-595, ISPRS, Bergamo, 6-7-8 febbraio 2019, doi: 10.5194/isprsarchives-XLII-2-W9-589-2019

Ruggiero, M., E., Torti, R., 2019. Disegno e comprensione del paesaggio: il virtuoso passaggio di scala nella rappresentazione digitale. DISEGNO, Vol. 5, pp. 59-68, Italy: Unione Italiana per il Disegno. http://dx.doi.org/10.26375/disegno.5.2019.08.

Tolle-kastenbein, R., 1993: Archeologia dell'acqua. La Cultura idraulica nel mondo classico. Milano, It: Longanesi \& C.

Toschi, I., Remondino, F., Orlandini, S., 2015: Mobile Mapping Systems: recenti sviluppi e caso applicativo. GEOmedia: V. 19 N. 4 (2015).

Trotta, F. (Strabone eds.), 2017: Geografia Iberia e Gallia. Vol. III - IV. Milano, IT: BUR Rizzoli

Vallerani, F., Visentin, F., 2019: Waterways and the Cultural Landscape. New York, USA: Routledge
Vallet, B. and Papelard, J.-P., 2015: Road orthophoto/dtm generation from mobile laser scanning, ISPRS Ann. Photogramm. Remote Sens. Spatial Inf. Sci., II-3/W5, 377-384, https://doi.org/10.5194/isprsannals-II-3-W5-377-2015, 2015.

Zhong, L., Cheng, L., Xu, H., Wu, Y., Chen, Y., Li, M., 2017: Segmentation of individual trees from TLS and MLS data. IEEE Journal of Selected Topics in Applied Earth Observations and Remote Sensing, 10(2), 774- 787. https://doi.org/10.1109/JSTARS.2016.2565519

Wallace, L., Lucieer, A., Watson C., 2014: Evaluating tree detection and segmentation routines on very high-resolution UAV Lidar data. IEEE Trans Geosci remote Sens, 52(12):76197628 